the prognosis by reducing the excess cardiovascular mortality in diabetic nephropathy.

We thank Dr Philip Hougaard for help and advice with the statistical analyses.

1 Andersen AR, Christiansen JS, Andersen JK, Kreiner S, Deckert T. Diabetic nephropathy in type 1 (insulin dependent) diabetes: an epidemiological study. Diabetologia 1983;25:496-501.

2 Krolewski AS, Warram JH, Christlieb AR, Busick EJ, Kahn CR. The changing natural history of nephropathy in type 1 diabetes. Am $\mathrm{J}$ Med 1985;78:785-94.

3 Borch-Johnsen K, Andersen PK, Deckert T. The effect of proteinuria on relative mortality in type 1 (insulin dependent) diabetes mellitus. on relative mortality in

4 Knowles $\mathrm{HC}$ Jr. Long term juvenile diabetes treated with unmeasured diet. Trans Assoc Am Physicians 1971;84:95-101.

5 Parving H-H, Hommel E, Mathiesen E, et al. Prevalence of microalbuminuria, arterial hypertension, retinopathy, and neuropathy in patients with insulin dependent diabetes. Br Med F 1988;296:156-60.

6 Borch-Johnsen K, Kreiner S. Proteinuria-value as predictor of cardiovascular mortality in insulin dependent diabetes mellitus. $\mathrm{Br} \mathrm{Med} \mathcal{J}$ 1987;294:1651-4

7 Eggers PW. Effect of transplantation on the medicare end-stage renal disease program. N Engl f Med 1988;381:223-9.

8 Mogensen CE. Long term antihypertensive treatment inhibiting progression of diabetic nephropathy. Br Med f 1982;285:685-8.

9 Parving $\mathrm{H}-\mathrm{H}$, Andersen AR, Smidt UM, Svendsen PA. Early aggressive antihypertensive treatment reduces rate of decline in kidney function in diabetic nephropathy. Lancet 1983;i:1175-9.

10 Biörck S, Nyberg G, Mulec H, Granerus G, Herlitz H, Aurell M. Beneficial effects of angiotensin converting enzyme inhibition on renal function in patients with diabetic nephropathy. Br Med f 1986;293:471-4.

11 Parving $\mathrm{H}-\mathrm{H}$, Andersen AR, Smidt UM, Hommel E, Mathiesen ER, Svendsen PA. Effect of antihypertensive treatment on kidney function in diabetic nephropathy BrMed f 1987;294:1443-7.

12 Parving $\mathrm{H}-\mathrm{H}$, Hommel E, Smidt UM. Protection of kidney function and decrease in albuminuria by captopril in insulin dependent diabetics with nephropathy. Br Med f 1988;297:1086-91.

13 Mortensen HB. Quantitative determination of haemoglobin $A_{\mathrm{lc}}$ by thin layer isoelectric focusing. I Chromatogr 1980;182:325-33.

14 Viberti GC, Bilous RW, Mackintosh D, Keen H. Monitoring glomerular function in diabetic nephropathy. Am F Med 1983;74:256-64

15 Parving H-H, Andersen AR, Hommel E, Smidt UM. Effect of antihypertensive treatment on diabetic nephropathy in insulin dependent diabetic patients. In: Friedman EA, L'Esperance FA, eds. Diabetic renal-retinal syndrome. Vol 3. New York: Grune and Stratton, 1986:183-90.

16 Cohen D, Dodds R, Viberti GC. Effect of protein restriction in insulin dependent diabetics at risk of nephropathy. Br.Med $\mathcal{F}$ 1987;294:795-8.

17 Nyberg G, Nordén G, Attman P-O, et al. Diabetic nephropathy: is dietary protein harmful? Journal of Diabetic Complications 1987;1:37-40.

18 Mauer SM, Steffes MW, Brown DM. The kidney in diabetes. Am f Med 1981;70:603-12.

19 Hasslacher C, Stech W, Wahe P, Ritz E. Blood pressure and metabolic control as risk factors for nephropathy in type 1 (insulin dependent) diabetes. Diabetologia 1985;28:6-1

20 Berglund J, Lins L-E, Lins P-E. Metabolic and blood pressure monitoring in diabetic renal failure. Acta Med Scand 1985;218:401-8.

21 Viberti G-C, Bilous RW, Mackintosh D, Bending JJ, Keen H. Long term correction of hyperglycaemia and progression of renal failure in insulin dependent diabetes. Br Med f 1983;286:598-602.

22 Nyberg G, Blohmé G, Nordén G. Impact of metabolic control in progression of clinical diabetic nephropathy. Diabetologia 1987;30:82-6.

23 Viberti GC, Keen H, Dodde R, Bending JJ. Metabolic control and progression of diabetic nephropathy. Diabetologia 1987;30:481-2.

24 Parving H-H, Smidt UM, Friisberg B, Bonnevie-Nielsen V, Andersen AR. A prospective study of glomerular filtration rate and arterial blood pressure in insulin dependent diabetics with diabetic nephropathy. Diabetologia 1981; 20:457-61.

25 Parving H-H, Andersen AR, Smidt UM, Oxenboll B, Edsberg B, Christiansen JS. Diabetic nephropathy and arterial hypertension. Diabetologia 1983; 34:10-12.

26 Brenner BM. Hemodynamically mediated glomerular injury and the progressive nature of kidney disease. Kidney Int 1983;23:647-55.

(Accepted 10 May 1989)
Nuffield Orthopaedic Centre, Oxford OX3 7LD Michael C Beverly, FRCS, orthopaedic senior registrar Roger Smith, FRCP, consultant physician

Northampton General Hospital, Northampton NN1 5BD

Trudy A Rider, FRCS, orthopaedic senior house officer

Hammersmith Hospital, London W12 0HS

Michael J Evans, FRCS, consultant orthopaedic surgeon

Correspondence to:

Mr Beverly,

30 Sheen Road, Richmond, Surrey TW9 $1 \mathrm{AW}$.

Br Med f 1989;299:233-5

\title{
Local bone mineral response to brief exercise that stresses the skeleton
}

\author{
Michael C Beverly, Trudy A Rider, Michael J Evans, Roger Smith
}

Abstract

Objective-To compare grip strength and bone mineral content in the forearm in women and to test the effects on bone mineral content of short periods of exercise that stresses the skeleton.

Design-Assessment of both wrists in 69 volunteers and of the non-fractured wrist in $\mathbf{3 0}$ patients followed by an exercise regimen entailing squeezing a tennis ball as hard as possible for $\mathbf{3 0}$ seconds each day for six weeks.

Setting-Old people's homes and outpatient departments of Hammersmith and Northampton general hospitals.

Patients - 99 Women, of whom 69 were volunteers and 30 had a fractured forearm.

Main outcome measure-Grip strength and bone mineral content after six weeks and at six months after the exercises had stopped.

Results-The bone mineral content of the women's forearms was measured with a densitometer and the grip strength with a semi-inflated bag connected to an anaeroid barometer. Measurements before exercise showed that the two variables correlated closely, irrespective of age, and that there were significant differences in both between the dominant and non-dominant arms of the volunteers. After six weeks of exercise there was a mean increase in grip strength of $14.5 \%(95 \%$ confidence interval 9.9 to $19.2 \%)$ and in bone mineral content of $3.4 \%(1.4$ to $5.3 \%)$ in the stressed forearms of the 77 women who attended for examination. After six months without exercise the improvements in the 33 women who attended for follow up had reversed. Women who had had a fractured forearm $(n=13)$, however, had continued to gain grip strength and bone mineral content in the arm that had not been injured.

Conclusions-Grip strength in the forearm is a good indicator of bone mineral content. Both variables may be increased by brief periods of stressful exercise. If this principle can be applied to the whole skeleton it may provide a means of reversing osteoporosis.

\section{Introduction}

Physical activity is commonly accepted to have some role in preventing and treating osteoporosis, ${ }^{1-3}$ but the role is unclear. ${ }^{4}$ Female marathon runners, for example, may become osteoporotic, ${ }^{5}$ and infantry recruits subjected to severe exercise developed either hypertrophy of the tibia or stress fractures. ${ }^{6}$ Pathological bone remodelling was shown by Wolff nearly a century ago, and Nilsson and Westlin showed that localised changes in bone density in athletes were related to the stresses put on their arms and legs during their particular sport. ${ }^{8}$ Rubin and Lanyon produced an osteogenic response to short periods of abnormal loading in the functionally isolated wing bone of a rooster. ${ }^{9}$

Patients with fractures of the arm or leg commonly develop a localised osteoporosis, which reverses as use returns. We examined the relation between bone mineral content in the forearm and the peak stress, equivalent to maximum grip strength, commonly experienced by the forearm and tried to modify grip strength in female volunteers and women with a fractured forearm.

\section{Subjects and methods}

We tested the grip strength of 99 women (69 volunteers and 30 patients with a fractured forearm) 
with a semi-inflated (at $40 \mathrm{~mm} \mathrm{Hg}$ ) bag connected to an anaeroid barometer with a scale of $0-600 \mathrm{~mm} \mathrm{Hg}$. The bone mineral density of their wrists was measured with a Molsgaard BDS1100A single photon absorption densitometer. ${ }^{10}$ This instrument measured absorption of photons of iodine- 125 by the forearm in a water bath and was calibrated for decay of the isotope twice daily. The bone mineral content was given in arbitrary units. Data corrected for the amount of fat and bone width of the women's forearms were ignored as these were unlikely to vary during the brief experiment.

The exercise regimen required each woman to squeeze a tennis ball as hard as possible three times consecutively, morning and evening, every day for six weeks; this took less than 30 seconds each day. The 69 volunteers had a mean (SD) age of 62 (16) years. They were randomly allocated to stress one forearm ( 34 to stress the right forearm and 35 to stress the left) while the other arm remained unexercised as a control. Their grip strength and bone mineral content were measured at six weeks. The 30 patients had a mean age of $53(21)$ years; they stressed their uninjured arm (15 stressed the right arm and 15 the left). Their grip strength and bone mineral content were measured at three and six weeks.

Six months after the exercise regimen had ended the women were asked to return at short notice for further measurements. Initial measurements were taken as $100 \%$, and paired $t$ tests of changes from these were used throughout, as in other studies. ${ }^{11}$ Statistical analysis was carried out by a Minitab program.

\section{Results}

In the 99 women examined both bone mineral content in the forearm and grip strength decreased with age $(\mathrm{r}=-0.746, \mathrm{p}<0.001$ and $\mathrm{r}=-0.645$, $\mathrm{p}<0.001$ respectively). Grip strength and bone mineral content before exercise correlated closely $(r=0.659$, $\mathrm{p}<0.001$; fig 1 ). Multiple regression analysis of bone mineral content against both age and grip strength gave the equation: bone mineral content $=44 \cdot 2-(0 \cdot 289 \times$ age $+(0.0285 \times$ grip strength $)$. The corresponding standard errors were 0.045 for age and 0.008 for grip strength. Grip strength, irrespective of age, is therefore a good predictor of bone mineral content in the forearm $(\mathrm{p}<0.001)$. Age and grip strength together accounted for $60.8 \%$ of the variance in bone mineral content.

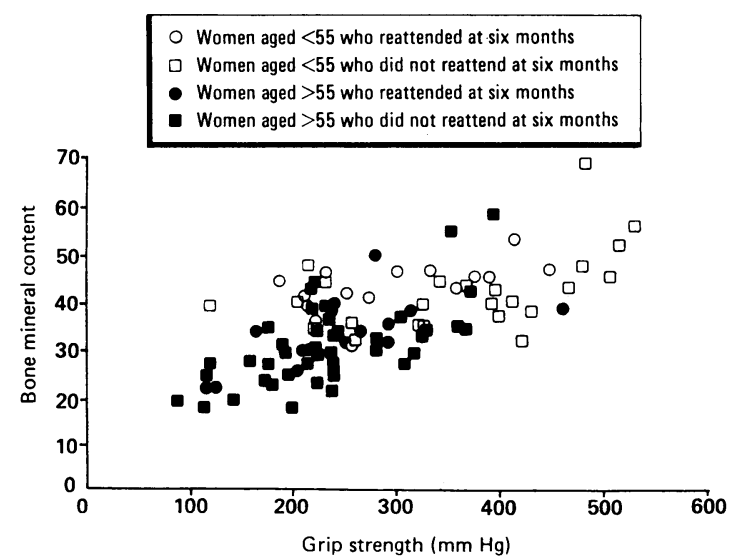

FIG 1-Correlation between bone mineral content (arbitrary units) and grip strength $(\mathrm{mm} \mathrm{Hg})$ before exercise in forearms of 99 women

Among the 69 volunteers there were significant differences between the dominant 65 right and four left) and non-dominant arms for both grip strength $(11.9 \%, \mathrm{p}<0.0003 ; 95 \%$ confidence interval 5.8 to $18 \cdot 1 \%)$ and bone mineral content $(2.7 \%, \mathrm{p}<0.02 ; 0.5$ to $4.9 \%$ ).

The 77 women who were examined at six weeks had a $14.5 \%(\mathrm{p}<0.0001,95 \%$ confidence interval 9.9 to $19 \cdot 2 \%)$ improvement in grip strength and a $3 \cdot 4 \%$ $(\mathrm{p}<0.001,1.4$ to $5.3 \%)$ improvement in bone mineral content in the exercised forearm. The 57 volunteers who reattended at six weeks had a mean gain of $12.5 \%$ $(\mathrm{p}<0.001,6.6$ to $18.4 \%)$ in grip strength and $3.1 \%$ $(\mathrm{p}<0.02,0.6$ to $5.6 \%)$ in bone mineral content in the exercised forearm (fig 2). There was also a rise in grip strength of $7 \cdot 4 \%(p<0.002,2 \cdot 8$ to $12 \cdot 0 \%)$ that was associated with a non-significant rise in bone content of $1.9 \%(\mathrm{p}<0.13,-0.6$ to $4.3 \%)$ in the unexercised arm; several women, however, admitted to having stressed both forearms.

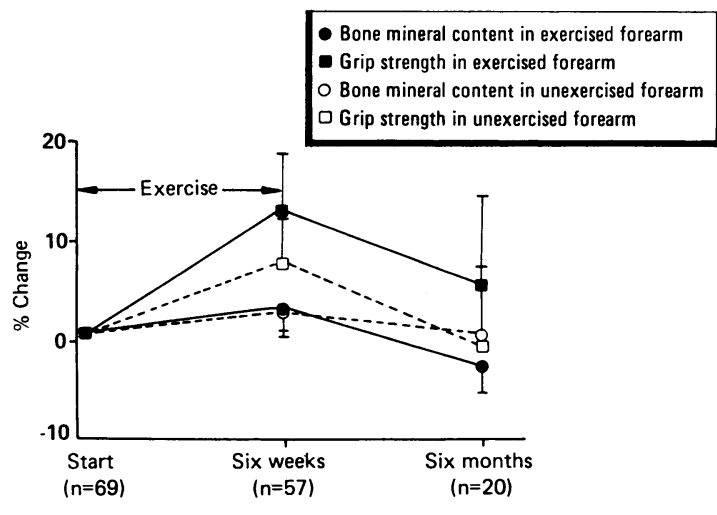

FIG 2-Percentage changes in grip strength and bone mineral content in exercised and unexercised forearms of 69 volunteers. Bars are $95 \%$ confidence intervals

Women with a fracture were seen at three and six weeks. The 27 who attended at three weeks had a $12.3 \%$ improvement in grip strength $(\mathrm{p}<0.001,5.9$ to $18.8 \%$ ) with a $4.8 \%$ rise in bone mineral content $(\mathrm{p}<0.0005,2 \cdot 4$ to $7 \cdot 1 \%)$. The 20 who also returned at six weeks had a $20.4 \%(p<0.0001,14.0$ to $26.8 \%)$ gain in grip strength and a $4.0 \%(\mathrm{p}<0.005,1.5$ to $6.5 \%)$ increase in bone mineral content (fig 3 ).

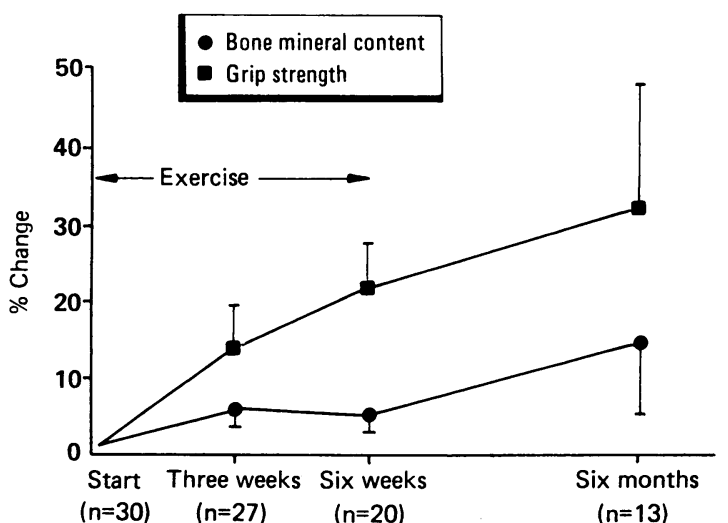

FIG 3-Percentage changes in grip strength and bone mineral content in the uninjured forearm of 30 patients with a fractured forearm. Bars are $95 \%$ confidence intervals

Women with or without a fracture who had gained more than $50 \mathrm{~mm} \mathrm{Hg}$ in grip strength after six weeks of exercise, (the "best exercisers") were analysed separately. Their $35.7 \%(p<0.0001,29 \cdot 1$ to $42 \cdot 3 \%)$ gain in strength was associated with a $4.7 \%(\mathrm{p}<0.04$, 0.2 to $9.3 \%$ ) gain in bone mineral content (fig 4 ).

In all, 33 women attended a recall six months after the exercise ended (figs 2-4). The volunteers $(n=20)$ had lost most of their gains (grip strength $5 \cdot 1 \%$ ( $p<0 \cdot 3,-4 \cdot 7$ to $14.9 \%$ ) and bone mineral content $-2.6 \%(\mathrm{p}<0.1,-5.6$ to $0.52 \%)$ of their initial measurements). Women who had had a fracture $(n=13)$, however, had continued to gain strength $(30.9 \%, \mathrm{p}<0.003 ; 12.8$ to $49.0 \%)$ and bone mineral 


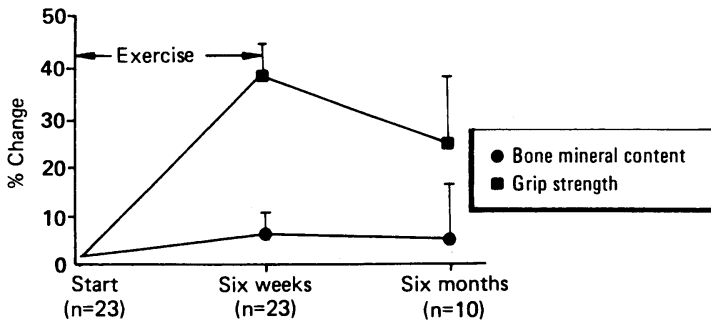

FIG 4-Percentage changes in grip strength and bone mineral content in the exercised arm for women who had a gain in grip strength of $>50$ $\mathrm{mm} \mathrm{Hg}$ at six weeks. Bars are $95 \%$ confidence intervals

content $(13 \cdot 3 \%, \mathrm{p}<0.02 ; 2.6$ to $24.0 \%)$ in their uninjured arm. Comparison of both forearms at six months showed that the exercised arm had $29 \cdot 1 \%$ ( $<<0.004,11.5$ to $46.7 \%$ ) greater grip strength and $4.9 \%(\mathrm{p}<0.14,-1.9$ to $11.7 \%)$ higher bone mineral content than the arm that had been injured. The best exercisers $(n=10)$ conserved some of their increases in strength and bone density at six months, but neither was significant.

The results at six weeks for the 33 women who were seen at six months showed a $20.6 \%(\mathrm{p}<0.0001,13.5$ to $27 \cdot 7 \%)$ improvement in grip and a $3 \cdot 4 \%(\mathrm{p}<0.036,0 \cdot 2$ to $6.5 \%$ ) improvement in bone mineral content in the exercised arm; their initial grip strength was $261 \mathrm{~mm}$ $\mathrm{Hg}$ (231 to $290 \mathrm{~mm} \mathrm{Hg}$ ) and bone mineral content 36.9 units (33.9 to 39.9 units). The initial grip strength in the exercised arm of the 66 women who did not reach the end of the study was $275 \mathrm{~mm} \mathrm{Hg}$ ( 249 to $301 \mathrm{~mm}$ $\mathrm{Hg}$ ) and their initial bone mineral content 33.9 units ( 31.4 to 36.4 units). Those who did not attend at six months were older (mean age 60.5 years) than those who did (mean age $56 \cdot 8$ years).

\section{Discussion}

As expected, our results showed that both grip strength and bone mineral content in the forearm fall with age, but we also found a close correlation between the two variables irrespective of age. In addition, the small but significant initial difference in both variables between the dominant and non-dominant arms of the 69 volunteers supports our hypothesis that a forearm's bone mineral content is related closely to the physical demands made on it by activities that require grip strength. We had assumed that a grip of maximum power stresses the skeleton of the forearm as much as any other activity that is performed commonly. We had not expected the change in grip strength in the unexercised arm, which was associated with a nonsignificant increase in bone mineral content. There was, however, insufficient emphasis in our instructions to prevent volunteers exercising both forearms, and several admitted to doing this.

We had also assumed that after a Colles' fracture the uninjured forearm is used more. This may be wrong: a manual worker might avoid physical stress when off work, whereas an independent retired person might be obliged to undertake more stressful activity with the intact arm. Women with fractures achieved a significant increase in bone mineral density by three weeks. Several of those with minor fractures were out of plaster before six weeks and were unlikely to attend hospital again, which may account for the non-linear results over three to six weeks. Similarly, frail volunteers were less likely to attend follow up clinics, and it was not feasible to retest some of those in old people's homes at six months. Those who attended six months after the exercise regimen ended were therefore likely to be the more motivated women who had originally done well with the exercises.

As numbers of women fell with succeeding visits the mean strength and bone mineral content rose. Measure- ments at six months showed a loss of the previous gains in grip strength and bone mineral content in all of the women except those who had had a fracture. It may be that after a fracture patients with apparently normal function continue to protect the injured arm from peak stresses by using the uninjured wrist for activities that require a powerful grip. They may thereby continue to increase both grip strength and bone mineral content in the non-fractured arm.

Changes in grip strength were mirrored by changes in bone mineral content at all stages, and this supports our contention that mineral content reflects quickly the physical demands made on bone. Muscle may be trained for great endurance without bulk by prolonged exercise, as in marathon runners, or for strength and bulk by isometric exercise, as in weight lifters. A similar analogy might apply to bone, in which short periods of skeletal stress may trigger osteogenesis more effectively than hours of gentler exercise.

Several questions remain-for example, Can this principle be applied to the entire skeleton? and What is the minimum daily requirement of skeletal stress? A few seconds of grip exercise each day may stress the forearm skeleton sufficiently to stimulate a local gain in bone mineral content. The best method of regularly stressing the whole skeleton of aging and reluctant women, however, remains to be shown.

This work was funded in part by the Wellcome Trust, the Porritt Fellowship, Oxford Regional Health Authority, and Research into Ageing. Statistical advice was provided by Chris Pierce of the Nuffield department of clinical medicine.

1 Anonymous. Consensus development conference: prophylaxis and treatmen of osteoporosis. Br Med f 1987;295:914-5.

2 Schapira D. Physical exercise in the prevention and treatment of osteoporosis: a review. F $R$ Soc Med 1988;81:461-3.

3 Cooper C, Barker DJP, Wickham C. Physical activity, muscle strength, and calcium intake in fracture of proximal femur in Britain. Br Med $\mathcal{J}$ 1988;297:1443-6.

4 Block JE, Smith R, Black D, Genant HK. Does exercise prevent osteoporosis? FAMA 1987;257:3115-7.

5 Drinkwater BL, Nilson K, Chestnut $\mathrm{CH}$, Bremner WJ, Shainholtz S, Southwort MB. Bone mineral content of amenorrheic and eumenorrheic athletes. N Engl B Med 1984;311:277-81.

6 Marguiles JY, Simkin A, Leichter I, et al. Effect of intense physical activity on the bone mineral content in the lower limbs of young adults. F Bone foint the bone mineral content in
Surg $[A m] 1986 ; 68: 1090-3$.

7 Wolff JD. Das Gesetz der Transformation der Knochen. Berlin: Hirschwald, 1892

8 Nilsson BE, Westlin NE. Bone density in athletes. Clin Orthop 1971;77:177 82.

9 Rubin CT, Lanyon LE. Regulation of bone formation by applied dynamic loads. F Bone foint Surg [Am]1984;66:397-402.

10 Christiansen C, Rodbro P, Jensen H. Bone mineral content of the forearm measured by photon absorptiometry. Principles and reliability. Scand f Clin Lab Invest 1975;35:323-30.

11 Chow R, Harrison JE, Notarius C. Effect of two randomised exercise programmes on bone mass of healthy postmenopausal women. Br Med $\mathcal{f}$ 1987;295:1441-4.

(Accepted 10 May 1989)

\section{Retraction in the light of new data \\ Altered calcitonin gene in a young patient with osteoporosis}

From M Alevizaki and S Legon: We recently reported the sequence of the calcitonin gene of a young male osteoporotic patient in whom no calcitonin could be detected (M Alevizaki, J C Stevenson, S I Girgis, I MacIntyre, S Legon. $\mathrm{Br}$ Med $\mathcal{f}$ 1989;298:1215-6 (6 May)). We noted a difference of a single base between this sequence and the previously published "normal" sequence in a region which may be important for the maturation of the mRNA, and we speculated that this might have caused his osteoporosis. However, using the polymerase chain reaction to screen normal subjects we now find this sequence to be widespread in the general population. We therefore conclude that this is a neutral polymorphism and is not responsible for the patient's condition. The cause of his calcitonin deficiency thus remains to be established. 